\title{
Renewable energy from municipal waste composting in Cesena, Italy: a case study
}

\author{
E. Piraccini ${ }^{1}$, B. Borsari ${ }^{2}$ \& A. Ceccaroni ${ }^{1}$ \\ ${ }^{1}$ Romagna Compost s.r.l., Via Spinelli 60, Cesena, Italy \\ ${ }^{2}$ Department of Biology, Winona State University, Winona, MN, USA
}

\begin{abstract}
Managing solid waste in urban areas remains a major challenge for achieving sustainability in the city. Our work presents the experience gained during the last decade in treating organic waste to produce electricity and compost in Cesena, Italy. Cesena is a city of about 100,000 inhabitants, located in the southeast corner of the Emilia-Romagna region (northern Italy). Since 2001 Romagna Compost Srl. has been disposing of organic waste from Cesena, with the aim of producing electricity and viable compost for local nurseries, city parks, gardens and other green spaces. The pre-existing composting plant (located in S. Carlo), which is $8 \mathrm{Km}$ southwest of the city, was renovated between 2008 and 2009 to eliminate bad odours, improve the quality of its effluent water and to reduce the overall environmental impact of the facility on the surrounding landscape. Through the process of anaerobic digestion, similar to that occurring in a cow's stomach, each ton of organic waste is now being converted into about 90 cubic meters of biogas of which $60 \%$ is methane and $180 \mathrm{kWh}$. The introduction of dry fermentation as a new treatment process allowed for a conversion of biomass with a dry matter content of up to $50 \%$ into compost and renewable energy. This system supplies about $10 \%$ of the electricity for domestic use in Cesena and it is the first dry anaerobic digestion plant in Italy. More data will be presented together with the ongoing effort to employ this facility also as an education centre and a demonstration site, to inspire other municipalities to achieve more sustainable methods and approaches of managing and recycling organic, municipal waste.
\end{abstract}

Keywords: anaerobic fermentation, biogas, compost, cogenerator, dry fermentation, organic waste, renewable energy, sustainability. 


\section{Introduction}

An increasing accumulation of municipal solid waste (MSW) has been challenging human communities in affluent countries for a long time thus, urging cities to develop feasible strategies and approaches for proper waste disposal through recycling and biogas production [1]. Harnessing biogas is aimed at generating renewable energy in the form of electrical power [2]. Present, dwindling non-renewable fossil fuel resources and increasing $\mathrm{CO}_{2}$ emissions responsible for global climate change are challenging modern society particularly in urban areas, to limit waste production [3] also because of increasing environmental and energy costs for its proper disposal. Therefore, it is becoming imperative to develop energy systems that are more sustainable and that may aid in producing renewable energy from byproducts and other waste resources. Compost and biogas production from organic waste are not old approaches in disposing of biomass that derives from agricultural and food wastes [4]. As a matter of fact, agricultural byproducts can be valuable inputs in an effort of producing renewable energy [2, 5-7]. However, the chronic crisis that has been affecting modern agriculture and the current fluctuation in oil prices upon which farming depends remains a tangible threat to large scale agriculture, both economically and environmentally [8]. Thus, the economy of industrialized countries remains heavily reliant on oil and other non renewable fuels to supply the energy needs of human communities with limited concerns to seek more viable solutions to resolve present and foreseeable challenges that affect the current energy crisis worldwide. On the other hand, organic wastes produced in cities appear to have become an interesting raw material, which appropriately decomposed generates biogas, in addition to electrical and thermal energy [9]. The purpose of our work consisted in showcasing the achievements but also present the challenges of day-to day operations in a new composting plant in northern Italy, capable of aiding the nearby city of Cesena with about 100,000 inhabitants to generate sustainably some of its electricity. This venture is the outcome of a partnership among several local organizations [5] and it is led by Romagna Compost that has been operating in the region since 2001 .

\section{The composting plant in Cesena, Italy}

Cesena is a province of the region Emilia-Romagna in northern Italy and it is located in its southeast corner, $14 \mathrm{Km}$. from the Adriatic Sea. The agricultural industry in this area is an economic activity of primary importance, which emphasizes in vegetables and fruits production. The compost plant has been in function since 2001. In 2008 it was renovated and enlarged (from 7,000 $\mathrm{m}^{2}$ to about $10,000 \mathrm{~m}^{2}$ ), in order to better accommodate the need of processing 30,000 tonnes of waste from the city (Cesena) and surrounding villages. This expansion was aimed at improving the existing treatment process of the separated collection of organic waste coming from the city.

The process is based on a two-phase oxidation of the biomass for a total duration of 90 days, with aerated oxidation and maturation in covered stalls. It 
includes an anaerobic fermentation (dry batch) in special compartments for 30 days and it is completed by 20 -day maturation in aerated windrows. Also, the new plant design included an addition of eleven stalls $\left(190 \mathrm{~m}^{2}\right.$ each) for anaerobic fermentation and six aerated windrows $\left(175 \mathrm{~m}^{2}\right)$. These were added to the old plant where some pre-existing areas retained their role in the process and where others have become converted into transformation areas, without disrupting the homogeneity of the whole complex (fig. 1). Romagna Compost Srl. disposes food waste, which derives from local farms and food processing plants of the province and households in Cesena. Additional biomass derives from parks waste and other green spaces, which yield materials such as leaves, grass clippings, tree branches and other woody wastes.
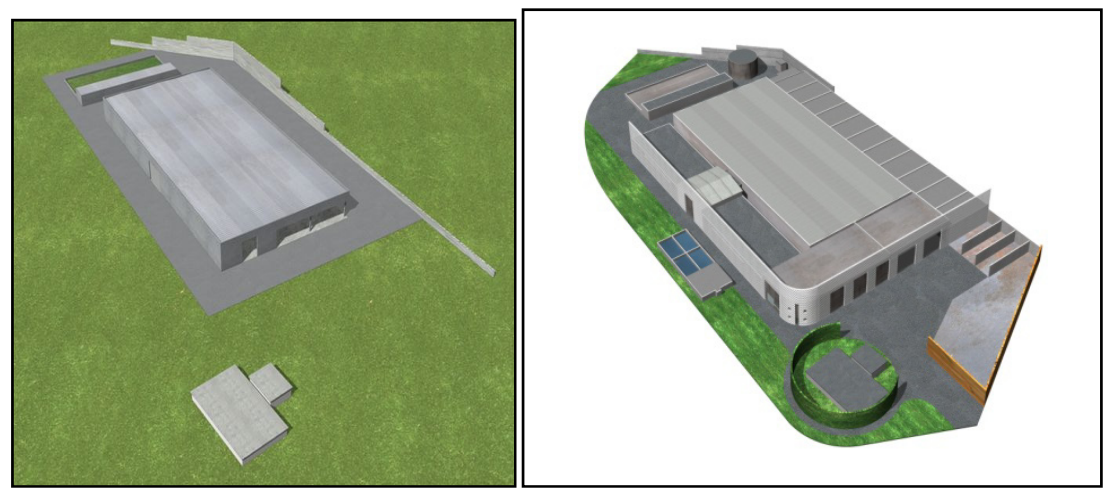

Figure 1: Composting plant of Romagna Compost Srl. in 2001 (left) and since its renovation (right), which was completed in 2009.

\section{Energy through the anaerobic digestion process, dry fermentation and cogeneration}

Although several approaches exist to convert biomass in viable compost $[1,2]$, biomass digestion through anaerobiosis is a very effective mode of biomass disposal for producing biogas. The process is driven by microbial activity and it begins via a hydrolysis of complex carbohydrates, followed by acetogenesis and methanogenesis [9]. These two processes were thought as priority features for the renovation of our pre-existing composting plant and the production of renewable electricity consisted in the main objective in the remodelling effort.

The process employed at Romagna Compost consists in filling up the chambers hermetically for 30 days with the collected organic waste. This biomass undergoes anaerobic digestion, which provides the opportunity of treating waste with a maximum content of dry matter almost to fifty percent. This is the first composting plant to have adopted such a technology in Italy [5]. The whole biodegradative process takes place in a single, cement fermenter where the biomass is not altered in anyway, nor inoculated, neither mixed. This technology is not a novel one however and many countries have employed it 
already for several years $[3,9]$. The homogenization of the fermenting biomass is insured by the leachate collection from the bottom of the fermenter, which is sprinkled from the top, back to the decomposing biomass, fig. 2 .

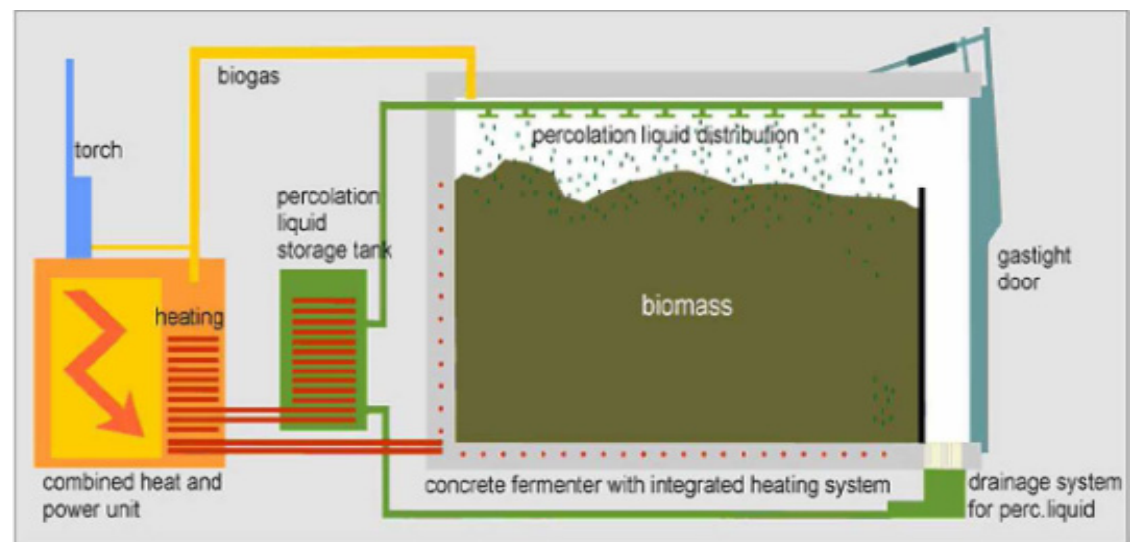

Figure 2: Schematic representation of the biogas and electricity producing system at Romagna Compost Srl., in Cesena, Italy.

In a second phase of the composting process an intensive bioxidation takes place through forced ventilation, which is followed by the aerobic stabilization of the biomass. At the completion of this process, heat and electricity are generated via internal combustion by cogenerators, which are fed biogas (containing about $60 \%$ methane), which was produced during the anaerobic digestion. The combination of anaerobic and aerobic processes is advantageous to improve the whole energy balance of the plant and the anaerobic phase generates a surplus of energy, which makes electricity production very effective [5].

Bad odours develop in consistent amount during the fermentation process and they can be a serious challenge to any composting facility. Their reduction requires a design of the plant, which is focusing on monitoring and controlling the whole composting process [10] since its early phase. At Romagna Compost bad odours are kept at minimum because they are produced in the closed fermenter and only during the production of biogas, which is immediately used by the cogenerators.

Cogeneration is the simultaneous production of electricity and steam, or heat in a single power plant and this process is the most efficient when compared with a separate production of electricity and steam (Edward Bryant, personal communication, 2011). The type of cogeneration used is based on the use of internal combustion engines that burn methane from biogas and produce electricity, which is fed directly, into the public grid. The heat generated in the process is employed to maintain constant $\left(37^{\circ} \mathrm{C}\right)$ the temperature in the anaerobic fermentation stalls and to heat, or cool off the plant offices, through a trigeneration system. 


\section{Data and discussion}

We report the data of the last two years (2010 and 2011) that represent the most significant results about the organic waste transformed into electricity at Romagna Compost Srl, table 1.

Table 1: $\quad$ Organic waste treated (ton) and transformed by Romagna Compost Srl in 2010 and 2011.

\begin{tabular}{|c|c|c|}
\hline Input/Output & 2010 & 2011 \\
\hline Treated waste (ton) & $\mathbf{3 0 , 0 0 0}$ & $\mathbf{3 9 , 5 0 0}$ \\
\hline $\begin{array}{c}\text { Cuttings and } \\
\text { prunings (ton) }\end{array}$ & $\mathbf{5 , 6 0 0}$ & $\mathbf{6 , 6 0 0}$ \\
\hline Biogas (m ${ }^{3}$ ) & $2.650,000$ & $3.150,000$ \\
\hline Electricity (kWh) & $5,250,000$ & $6,500,000$ \\
\hline Compost (ton) & 2,400 & 4,800 \\
\hline Biostabilized (ton) & 6,500 & 6,500 \\
\hline $\begin{array}{c}\text { Non-reusable fraction } \\
\text { (ton) }\end{array}$ & 1,500 & 4,800 \\
\hline Eluates $\left(\mathrm{m}^{3}\right)$ & 10,000 & 10,000 \\
\hline
\end{tabular}

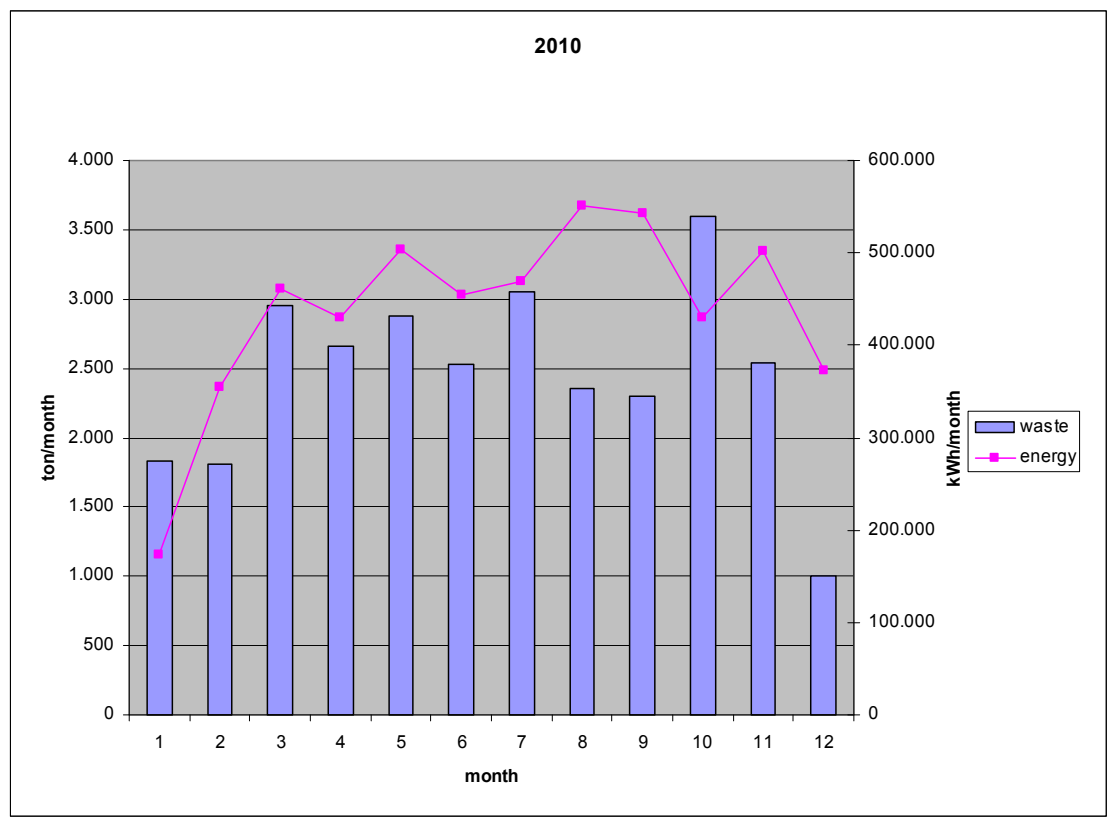

Figure 3: Relationship between the mass of organic waste treated (ton) and electricity generated every month in 2010 . 
The compost produced is a valuable soil amendment for agricultural fields, whereas the biostabilized (compost) is not suitable for farming purposes and it is used as a topping to cover landfills. The non-reusable fraction is non biodegradable and it is disposed in landfills. With the term 'eluates' we refer to any liquid material originating from any phase of the treatment and transformation processes. All eluates undergo depuration and they are discharged into the public sewage system. Additional data illustrate the correlation between electricity production and the amount (tons) of the monthly treated waste within the same timeframe (2010 and 2011), (figs. 3 and 4). It should be noted that biogas production (and consequently the production of electricity) is directly proportional to the mass of treated waste.

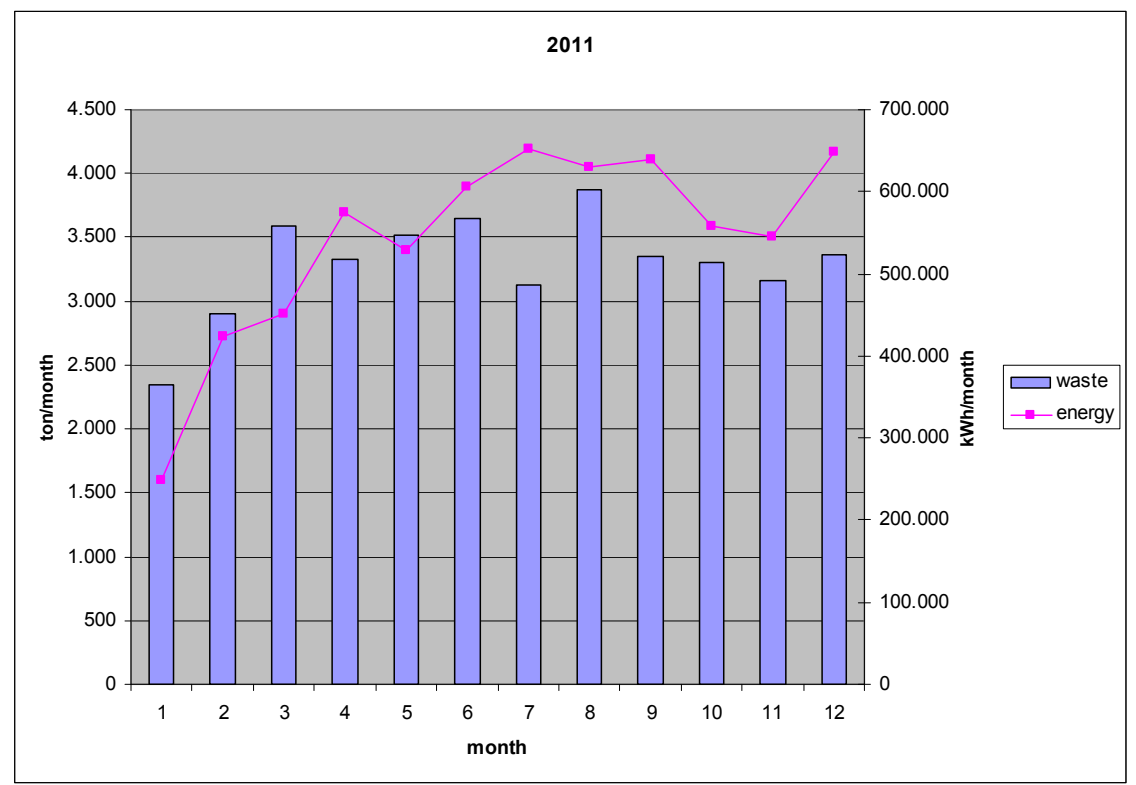

Figure 4: Relationship between the mass of organic waste treated (ton) and electricity generated every month in 2011 .

\section{Conclusion and future developments}

Composting organic waste offers tremendous opportunities to achieve sustainability in urban areas. Although effective methods exist already to produce electricity from the biogas spewed by municipal landfills [11], the advantages of working with organic waste are multifaceted. Through our approach the community has been engaged in a collective effort to become more educated about the importance of recycling and converting waste into electricity. However, from our experience we learned that a clear understanding and 
management of biomass digestion remains fundamental to achieve outstanding, renewable energy yields.

The uninterrupted waste processing for the last two, consecutive years at our plant has demonstrated the following:

- Dry, anaerobic digestion is an efficient process for our type of biomass (organic waste);

- Satisfying energy yields have been produced from $90 \mathrm{~m}^{3} /$ ton of treated waste;

- The biological process (fermentation) is safe, effective and manageable to yield renewable electricity.

In addition to this, the renewable production of electricity (from $5 \times 10^{6} \mathrm{kWh}$ in 2010 to $6.5 \times 10^{6}$ in 2011 suggest that the plant posses the capability of yielding up to $165 \mathrm{kWh}$ per ton of biomass. This indicates that a typical four-people family in Cesena, Italy can be supplied with about the $10 \%$ of its electricity needs from the organic waste processed at Romagna Compost Srl. Secondly, the ultimate output of the composting process (the compost) becomes a valuable resource for local agriculture. With both compost and renewable energy production from waste biomass the plant offsets about $85 \mathrm{~kg}$ of $\mathrm{CO}_{2}$ for each ton of composted biomass [12]. Therefore, about 32,000 tons of $\mathrm{CO}_{2} /$ year is sequestered by our composting plant contributing effectively to reduce the ecological footprint of Cesena, Italy. In the near future, we hope to achieve a higher level $(>30 \%)$ of heat harnessing from the composting plant, which could also be supplied to the community. A feasibility study to employ a photovoltaic system is being considered to augment the kWh of electricity output from the plant. Finally, the treatment and processing of woody biomass is being studied to produce more renewable energy from waste in the form of pellets that could be burned in stoves.

\section{Acknowledgements}

The experience of Romagna Compost Srl. emerged from the combination of several local partners (HeraAmbiente, Romagna Compost, Amadori, Orogel; Gruppo Sfir, CAC, Formula Servizi), all committed to develop and implement a more efficient system to dispose of large amounts of biomass while producing electricity from waste. The partnership among these local organizations remains a pivotal feature that made possible the realization of our unique composting facility.

\section{References}

[1] Diaz, L.F., Savage, G. M, \& Golueke, C. G., Composting of Municipal Waste. In: Tchobanoglous, G. and Kreith, F. eds. Solid Waste Handbook. $2^{\text {nd }}$ Ed. McGraw Hill, New York, NY, 2002.

[2] Tchobanoglous, G., Solid Waste Management in Environmental Engineering. In: Salvato, J. A., Nemerow, N. L. and Agardy, F. J. eds. 
Environmental Engineering, $5^{\text {th }}$ Ed. John Wiley \& Sons Inc., Hoboken, NJ, 2003.

[3] Chromec, P. R. and Ferraro, F. A., Waste-to-Energy in the context of global warming. Proceedings of the $16^{\text {th }}$ Annual North American Waste-to-Energy Conference, Philadelphia, PA, pp. 1-11, 2008.

[4] Riggle, D., Revival time for composting food industry wastes. BioCycle, 30(5), pp. 35-37, 1989.

[5] Taverna, A., L'Energia da Compostaggio. Recycle, (marzo), pp. 27-30, 2010.

[6] Deublein, D. \& Steinhauser, A. (Eds.), Biogas from Waste and Renewable Resources: An Introduction. Wiley-VCH Verlag Gmbh \& Co. KGaA, Weiheim, Germany. pp. 448, 2008.

[7] Kaparaju, P., Serrano, M., Thomsen, A. B., Kongjan, P., Angelidaki, I., Bioethanol, biohydrogen and biogas production from wheat straw in a biorefinery concept. Bioresource Technology 100, pp. 2562-2568, 2009.

[8] Borsari, B., Onwueme, I., Kreidermacher, E. and Terril, T., Renewable energy from restored prairie plots in southeastern Minnesota, USA. Proceedings of the $2^{\text {nd }}$ International Conference "Energy and Sustainability". pp. 137-145. In: A. Mammoli and C. A. Brebbia, eds. WIT Transactions on Ecology and the Environment, Vol. 121. Wessex Institute of Technology Press, 538 pp., 2009.

[9] Jithendran, V. N., Varma, A. R., Dileepkumar, M., Sahuji, K.G., Ushakumari, G. K. J., Specifications, Standards, Unit Cost, O\&M Protocols and Contract Conditions for MSW Treatment Plants Using Composting, Vermicomposting and Biomethanation. Rep. Expert Committee. Local Self Govt. Dept., Govt of Kerala, India, pp. 43, 2008.

[10] Haug, R. T., Composting process design criteria parts I, II, and III. BioCycle, August pp. 38-43, September, pp. 33-39, October, pp. 53-57, 1986.

[11] Duffy, D. P., Landfill Gas to Energy: Means and Methods, MSW Management, Jan./Feb., pp. 16-22, 2010.

[12] Smith, A., Brown, K., Ogilvie, S., Rushton, K., Bates J., Waste management options and climate change: final report to the European Commission, DG Environment. AEA Technology plc, pp. 224, 2001. 